Henrik Bergqvist*

\title{
Swedish modal particles as markers of engagement: Evidence from distribution and frequency
}

https://doi.org/10.1515/flin-2020-2047

Received February 21, 2020; accepted April 1, 2020

\begin{abstract}
The paper analyses the Swedish modal particles $j u$ and $v a ̈ l$ as markers of engagement. This analysis finds support in the distribution and frequency of $j u$ and $v a ̈ l$ in a corpus of spoken Swedish along with an examination of existing accounts concerning the semantics of the investigated forms. Engagement encodes differences in the distribution of knowledge and/or attention between the speaker and the addressee, where the basic semantic contrast consists of the speaker asserting an assumption about the addressee's knowledge of/attention to an event as either shared, or non-shared with the speaker. $J u$ and väl are paradigmatically contrastive in signaling shared access to an event from the point of view of the speaker, or the addressee: ju signals shared access to an event and at the same time places the epistemic authority with the speaker, and väl signals shared access to an event, placing the epistemic authority with the addressee. Analytical support for $j u$ and $v a ̈ l$ as markers of engagement comes from the distribution of both forms with first person (jag), second person $(d u)$, and generic (man) subject pronouns.
\end{abstract}

Keywords: engagement, modal particles, egophoricity, epistemic authority

\section{Introduction}

This paper analyses the Swedish modal particles $j u$ and $v a ̈ l$ as markers of engagement (Evans et al. 2018a, 2018b). This analysis finds support in the distribution and frequency of $j u$ and $v a ̈ l$ in a corpus of spoken Swedish (Löfström 1988; see Section 5.1 below) along with an examination of existing accounts concerning

\footnotetext{
*Corresponding author: Henrik Bergqvist, Department of Linguistics, Stockholm University, Universitetsvägen 10 C, Stockholm, 106 91, Sweden, E-mail: henrik.bergqvist@ling.su.se. https://orcid.org/0000-0001-6114-5527
} 
the semantics of the investigated forms. Engagement is a recently proposed notional domain that targets the epistemic perspectives of the speech-act participants, signaling differences in the distribution of knowledge and/or attention between the speaker and the addressee. The basic semantic contrast consists of the speaker asserting an assumption about the addressee's knowledge of/attention to an event $(e)$ as either shared, or non-shared with the speaker. This contrast can be paraphrased as 'I know $e$ and I assume that you know $e$ too', vs. 'I know $e$ and I assume that you do not' (cf. 'complex perspective', Evans 2005; cf. 'complex epistemic perspective', Bergqvist 2015, 2016, 2017). Engagement may thus be viewed as a form of socio-centric modality, where the speaker's assertion contains an embedded assertion assumed to belong to the addressee (see Bergqvist 2018a; cf. Kockelman 2004, 'secondary stances').

Modal particles in Swedish are not an obligatory clausal element and they are usually not viewed as a grammatical category comparable to some tense-aspect markers, a status they share with other discourse particles in Swedish (e.g., Lindström 2008). However, in line with observations regarding the role of frequency and distribution in the evolution of grammar (Bybee et al. 1994), one may argue that the grammatical status of $j u$ and $v a ̈ l$ should be evaluated based, in part, on their distributional characteristics and how they co-vary with other grammatical categories. Not only are modal particles frequent in spoken Swedish, they are also predictably connected to the egophoric pronouns, jag, $d u$, and man (i.e., first, second, and generic subject forms; see Dahl 2000; and Section 3, below). This connection results from the proposed semantics of $j u$ and $v a ̈ l$, viz. to signal shared access/knowledge to/of an event and the epistemic authority of the speaker $(j u)$ and the addressee (väl; see Section 4). With respect to the theme of the present Special Issue, the grammatical status of epistemic markers is an issue that requires further study for an improved understanding of epistemic marking in language. The distribution and frequency of epistemic markers, including modal particles, is an under-investigated part of the puzzle that can contribute to the confirmation/ rejection of hypotheses based on other grammatical (morpho-syntactic) characteristics and the use of forms in discourse. From a methodological perspective, this requires access to large-scale corpora, a resource that is seldom available for nonEuropean minority languages. ${ }^{1}$

The present paper will demonstrate formal and functional similarities between Swedish modal particles and engagement markers, as they have been described in

1 Compared to the other papers in this volume, which all discuss methodological issues with reference to smaller, non-European minority languages, the corpora available for an offical, national language like Swedish is large enough for distributional patterns to emerge even though their statistical significance may remain limited. 
the literature (see Section 2, below). The paper argues for a partly novel perspective on an important aspect of social cognition in grammar, given that the core function of engagement is to situate information between the speech-act participants by specifying cognitive access and involvement in a socio-cognitive sense. Instead of analyzing perceptual-cognitive access as a process within a solitary speaker, engagement puts emphasis on the speaker's awareness of the addressee's corresponding access. Additionally, the paper contributes to the exploration of what aspects of interaction and the interpersonal context are available for becoming encoded in grammar.

The two main claims of this paper are that the modal particles $j u$ and $v a ̈ l$ in Swedish may be analyzed using the notion of engagement and that support for this proposal comes from the distribution of both forms with first (jag), second ( $d u$ ), and generic (man) person subject pronouns. Ju and $v a ̈ l$ are paradigmatically contrastive in signaling shared access to an event from the point of view of the speaker or the addressee: ju signals shared access to an event and at the same time places the epistemic authority with the speaker, while $v a ̈ l$ signals shared access to an event placing the epistemic authority with the addressee. This characterization finds support in the literature (see Section 4.2), and a systematic comparison of ju and $v a ̈ l$ in terms of their co-distribution with pronouns adds additional support.

In the present paper, the notion of engagement is introduced in Section 2 and the related notions of egophoricity and egophoric marking are discussed in Section 3. These three notions have relevance for the Swedish modal particles ju and väl, which are discussed in Section 4. Section 5 accounts for the frequency and distribution of $j u$ and $v a ̈ l$, and Section 6 considers the implications of the results of the study and summarizes its main points.

\section{A definition of engagement}

The notion of engagement was proposed by Landaburu (2007) for Andoke (Isolate, Colombia), where there is a set of prefixes that signal contrastive configurations of the speaker's and the addressee's epistemic perspectives in terms of sensory access and attention. Evans et al. (2018a: 110) adopt Landaburu's term to account for "grammaticalised means for encoding the relative mental directedness of speaker and addressee towards an entity or state of affairs". Such grammatical means include both demonstratives and morphemes found with nominal and verbal predicates. Evans et al. analyze these as acting on different levels in language, namely on entities, propositions, and meta-propositions. Leaving aside engagement semantics in demonstratives (see e.g., Burenhult 2003 for Jahai, in Evans et al. 2018a: 128-130), we may take the system described for Kogi, below, as an 
example of a language where propositional engagement marking signals the speaker's assertion of an event together with assumptions regarding the addressee's shared, or non-shared knowledge/awareness of the same event.

\subsection{Engagement in Kogi}

In Kogi (Arwako-Chibchan; Bergqvist 2016; Knuchel 2019; cf. Ortíz Ricaurte 1994), four auxiliary prefixes encode engagement. ${ }^{2}$ These prefixes may be divided into two sets that take the speaker and the addressee as their respective starting points. A focus on the perspective of the speaker is found with $n a-/ n i-$, where $n a-$ means that the speaker knows $e$ and expects the addressee to be unaware of $e(1 \mathrm{a})$, and $n i$ means that the speaker knows $e$ and expects the addressee to know $e$ too (1b).
a. kwisa-té na-nuk-kú
dance-IMPF SPKR.ASYM-be.LOC-1S
'I am/was dancing.' \{informing\}
b. kwisa-té ni-nuk-kú
dance-IMPF SPKR.SYM-be.LOC-1s
'I am/was dancing.' \{confirming

$\mathrm{Na}-/ \mathrm{ni}^{-}$are in turn contrasted to sha-/shi-, which encode a corresponding distinction in terms of non-shared/shared knowledge from the addressee's perspective. sha-means that the speaker expects the addressee to know $e$ while the speaker is unaware of $e(2 \mathrm{a})$, and shi- means that the speaker expects the addressee to know $e$, and the speaker knows $e$ too (2b). ${ }^{3}$
a. nas hanchibé sha-kwísa=tuk-(k)u
1S.IND good ADR.ASYM-dance=be.LOC-1s
'I am dancing well (?)' \{in your opinion $\}$

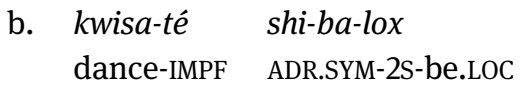
'You are/were dancing (?)' \{confirming\}

Shi-/sha- are used to signal the speaker's acknowledgment of the addressee as primary knower, but at the same time encodes the speaker's assertion (without

\footnotetext{
2 Bergqvist (2015, 2016, 2017) discusses the Kogi system using the term 'complex epistemic perspective' without arguing for a more general applicability of this term to similar systems and forms attested in the literature although the possibility is considered.

3 In (2a), the speaker's unawareness means that s/he lacks knowledge of the estimated quality of dancing as being good, or bad. It is the entire proposition that is at stake, not just the baer act of dancing.
} 
reduced certainty) of a talked-about event. In Kogi, we thus find two semantic parameters that pertain to the notion of engagement; firstly, there is the parameter of accessibility (see Bergqvist and Knuchel 2019), which can be shared or nonshared between the speaker and the addressee, secondly, there is the notion of epistemic authority, which warrants the separation between $n a-/ n i-$ and sha-/shiinto speaker and addressee-perspective forms. This separation foreshadows the notion of egophoric marking below, which encodes the involvement of the speechact participants and the resulting epistemic authority from such involvement (see Section 3.1).

On a conceptual level, engagement may be thought of in terms of intersubjectivity, a notion that extends the subjective perspective of the speaker to include the speaker's attention to the hearer/addressee (cf. Benveniste 1971; Traugott and Dasher 2002). However, intersubjectivity arguably exists on several levels in language: a primary intersubjectivity (Trevarthen 1979) that underlies language as a conventionalized system of communication, and subsequent 'intersubjectivities' (Scott-Phillips 2015) that develop later, and which are more closely associated with Machiavellian skills of aligning perspectives by means of coercion, argumentation, and deference (cf. Verhagen 2005). It is these later stages of intersubjective awareness that underlie the notion of engagement in grammar.

\subsection{Issues in the exploration of engagement}

The notion of engagement constitutes a recent proposal, and there are several descriptive and analytical issues that require attention in attempts to define this category, both with respect to its inherent properties and its boundaries against other already attested categories. The present paper contributes to this ongoing exploration by considering Swedish modal particles as markers of engagement.

A reasonable assumption is that lexical resources for expressing engagement are available in any and all languages. Equivalents of English adverbs and adverblike constructions such as obviously, of course, you know, actually, in my opinion have been noted from the point of view of epistemic modality (e.g., Simon-Vandenbergen and Aijmer 2007), of illocutionary force modification ('mitigation' and 'attenuation'; Holmes 1984), and discourse theoretical perspectives (e.g., Tree and Schrock 2002; Östman 1981). However, in delineating the properties of a notional domain and its expression in language, a focus may justifiably be placed on grammaticalized forms and constructions. The grammatical status of modal particles makes for an interesting topic of study in this context, given their status as partly grammaticalized forms. 
The grammatical status of forms as inflections or particles has bearing on meaning content, semantic scope, and degree of obligatoriness. Particles and affixes display differences corresponding to their respective degree of grammaticalization. Semantic complexity is reduced in inflections to target a relatively small number of semantic contrasts. A free-standing particle, on the other hand, may host many shades of (pragmatic) meaning as reflected by its peripheral status in the sentence/utterance. The semantic scope of inflections and particles/enclitics also differs, with an inflection sometimes only having scope over the verbal core, whereas particles may target an entire proposition or even sets of (interconnected) propositions.

There is also an expectation that members of a verbal category signal aspects of meaning belonging to a notional domain. A traditional (Reichenbachian) conceptualization of tense signals the location in time of an event with respect to the moment of utterance (see Klein 1994, for a more recent development and formulation of this basic model) and evidentiality has been proposed to signal the 'mode of access' (Plungian 2010) that the speaker has for a talked-about event. In the ongoing exploration of engagement, it is clear that forms of engagement denote a wider definition of epistemicity including not only knowledge and belief, but also attention and expectation as part of the speech participants' perspective in talking about an event. However, the use of forms in a language like Kogi reveals a correspondence between encoded meaning and a variety of functions depending on communicative intentions and pragmatically implied meaning. These include, among other things, rights to knowledge, deference/assertiveness, mitigation/ attenuation, and politeness. A definition of engagement must weigh such interactive considerations against proposed semantic contrasts in the exploration of forms.

A functional overlap between categories that is expected to be consequential to the analysis of engagement lies in how such markers express aspects of sentence-type in terms of declarative/assertive and interrogative utterances. In Kogi, one of the striking features of the system is the separation between speakerperspective and addressee-perspective forms that must be regarded as declarative from a formal standpoint (see Bergqvist 2016, for details). In a speech-act sense, addressee-perspective forms may convey requests or questions, but they do so in the form of an assertion entailing the commitment of the speaker. At present, it is unclear if this functional overlap is a significant feature of engagement systems more generally or if this is a language-specific feature found in Kogi (see Section 2.1, above). Another category interaction is found in the way markers of speaker asymmetry in Kogi produce an implied tense-shift (past) barring contextual cues to anchor an event in the present. This is a consequence of the pragmatics of asserting an event that is observable by both speech participants as only belonging to the 
speaker (in the case of non-shared knowledge/attention to an event). This produces an implication that the talked-about event is in the past, in order for the use of such a marker to be pragmatically felicitous. Aside from such conceptual overlaps, engagement semantics has also been found with evidential and egophoric markers (see directly below). A hypothesis awaiting confirmation is that any deictic form, which refers to some aspect of the speech situation (cf. speech event, Jakobson 1990 [1957]) is susceptible to harboring engagement semantics resulting from a process of intersubjectification (Bergqvist 2018b; cf. Traugott and Dasher 2002).

As Section 4.2 will show, the proposal that (Swedish) modal particles instantiate engagement semantics, has something to offer to the ongoing exploration of this notion. The semi-grammaticalized status of modal particles and their denomination as 'particles', makes it challenging to pin-point their semantics, but their distribution and frequency may provide analytical support for the proposed analysis (Section 5).

\section{Egophoricity in discourse and grammar}

Dahl (2000) defines 'egophoricity’ as reference to the speech-act participants (i.e., speaker and addressee) along with generic (person) reference (you/one, Swe. man) and logophorics, which mark co-reference between subjects in main and subordinate clauses (e.g., David ${ }_{i}$ said he $e_{i}\left[\log _{\text {ophoric] }}\right.$ will go to the party; see Dimmendaal 2001, for a detailed account of logophorics in African languages). Dahl's paper accounts for egophoricity with animate/inanimate arguments according to predicate type and valency (transitive/intransitive) and finds that the majority of all animate arguments in a corpus of Swedish conversations are egophoric. With mental verbs (e.g., veta 'know', tänka 'think', hoppas 'hope') the percentage of egophoric subjects is $82 \%$ of all animate subjects and with transitive verbs, it is $61 \%$. Only with copular verbs (vara 'be', bli 'become', heta 'be called', finnas 'be/ exist') is the percentage below 50\% (42\%). With copular verbs, 'allophoric' reference (i.e., third person) is more common (Dahl 2000: 47). Dahl also finds support for the generalizability of these percentages in data-sets of spoken English and Spanish, which agree with the distribution of Swedish egophoric pronouns. Dahl's investigation cannot be detailed here due to limitations of space, but the following observations have special relevance for the purposes of the present study: (i) the majority of all animate subjects in spoken Swedish are egophoric, (ii) this fact is restricted to conversations in spoken Swedish; in written Swedish the percentage of egophoric arguments drops drastically, (iii) the percentage of egophoric arguments is higher when an argument can only be animate (e.g., with mental verbs), 
(iv) the distribution of egophoric arguments in conversations cannot be accounted for by drawing on notions such as topicality and/or viewpoint but is simply a reflection of how people talk and what they talk about.

\subsection{Egophoric marking}

The term egophoricity has acquired a different meaning in the literature on epistemic marking. In this field of research, the term is used to distinguish between forms that signal the speaker's (or the addressee's) involvement and subsequent epistemic authority from forms that signal the non-involvement of the speaker/ addressee, mainly targeting events involving third person subjects (Floyd et al. 2018; cf. Bergqvist and Knuchel 2017). Egophorics in this sense, reflect a speech-act participant's primary knowledge of his/her own actions and of events that somehow involve them. When referring to the actions of a third party, knowledge about such actions usually does not come from direct involvement but rests on more indirect forms of access (e.g., sight, inference, hearsay), thus producing nonegophoric marking. In order to establish a separation between Dahl's use of the term egophoricity from the epistemic use of the same term, the present paper will use the term 'egophoric marking' for epistemic markers that refer to the involvement of the speech-act participants.

Egophoric marking systems are not common in the world's languages, but they are found in different parts of the world, such as the Himalayas (e.g., Hale 1980), the Caucasus (e.g., Creissels 2008), and South America (e.g., Curnow 2002; see Floyd et al. 2018, for details). ${ }^{4}$ A commonly cited example comes from Kathmandu Newar, where the egophoric marker (indicated by a long vowel) occurs in past contexts with first-person subjects in declaratives and second-person subjects in interrogatives. Third-person subjects are always non-egophoric. In Example (3), $-\bar{a}$ is egophoric and $-a$ is non-egophoric with the past tense form of the verb wane 'go': ${ }^{5}$
a. ji ana wanā
1s there go.EGo
'I went there.'
b. cha ana wanā lā
2s there go.EGO INTERR
'Did you go there?'

4 Since the publication of Floyd et al. (2018) survey, an attested instance of egophoric marking has been described for Dhivehi in the Maldives by Jonathon Lum (2020), thus adding South Central Asia to the areas of the world where egophoric marking has been attested.

5 Hale (1980) uses the terms 'conjunct'/'disjunct'. 

c. cha ana wana
2s there go.NON.EGO
'You went there.'

d. wa ana wana

3s there go.NON.EGO

'He went there.'

(Hale 1980: 95)

In Newar, first-person subjects may also combine with egophoric marking in (quasi-interrogative) rhetorical contexts. Likewise, second-person subjects may combine with non-egophoric marking in interrogatives, to produce a rhetorical utterance. There are also restrictions on what predicates may take egophoric marking, where only volitional predicates are available (Hale 1980: 96). An active predicate that would be available for egophoric marking with a first-person subject is interpreted as resulting in an involuntary act when marked non-egophoric.

$$
\begin{array}{lll}
\text { a. } & j i \quad \text { danā } \\
& \text { 1s go.EGO } \\
& \text { 'I got up (voluntarily)' } \\
\text { b. } & j i \quad \text { dana } \\
& \text { 1s go.NON.EGO } \\
& \text { 'I got up (involuntarily)' } \\
& \text { (Hale 1980: 99) }
\end{array}
$$

Egophoric marking in Newar consists of a system that may be regarded as narrow in the sense that it is encoded by an inflection with past verb forms and specifically targets the speaker's volition and intentional actions (see Creissels 2008; Floyd et al. 2018, for a discussion of relevant semantic parameters in egophoric marking). Any use of egophoric markers in Newar that go outside the default distribution against subject-person markers and sentence-type, produces a pragmatically conditioned change according to the parameters of volitional involvement and sub-sequential epistemic authority (see Bergqvist and Knuchel 2017, for an extended discussion). Egophorics in other languages sometimes have different distributions and restrictions for their use, and such differences may also be reflected by form. Awa Pit (Curnow 2002) is a Barbacoan language, where egophoric marking can also be used to imply the presence of a speaker that is affected by an event that they had no control over. 
Non-egophoric marking with the same construction nullifies the speaker's affectedness:
a. pina alu ki-ma-ti-s
very rain do-COMP-PST-EGO
'It rained heavily [on me].'
b. pina alu ki-ma-ti-zi
very rain do-COMP-PST-NON.EGO
'It rained heavily.'
(Curnow 2002: 620)

It appears that egophoric marking has wide applicability to denote the speech-act participant's claim of epistemic authority based on different kinds of involvement. Systems vary in terms of what predicates may inflect for egophoric marking but also how salient the involvement of the speaker/addressee is in a talked-about event, whether they are agentive subjects or merely affected participants.

Egophoric reference is present in forms that encode various aspects of the speaking subject(s) in discourse; in the best studied case, pronouns and person markers with the verb signal argument identity/animacy, but the default, epistemic status of the speaking subject also signals aspects of involvement as grounds for claiming epistemic authority. The distributional features of egophoric reference in discourse has also been noted in efforts to account for (epistemic) egophoric marking, which runs conceptually parallel to (generic) egophoric reference (see San Roque et al. 2018: 66-67).

\subsection{Egophoric 'territories of information'}

The privileged position of the speech-act participants with respect to events that involve (one, or both, of) them has also been described using the term "'territories of information' (Kamio 1997), which was coined to account for the distribution and use of clause-final discourse particles in Japanese. Kamio (1997) outlines the kinds of information (objects, events and states) that belongs to one speech-act participant over the other, thus marking that information as being in the territory of that participant: 1) information obtained from internal or direct experience, 2) detailed professional expertise/knowledge, 3) reliable information that one of the speechact participants commits to, 4) information about persons, objects, events and facts close to one of the speech-act participants, including personal information (Kamio 1997: 39).

We may connect the dominance of egophoric referents in spoken discourse primarily to the first item of this list, namely that a speech-act participant's 
internal, or direct experience constitutes grounds for claiming such experiences as part of their epistemic territory. Experiences of this kind are reflected in mental, transitive, and intransitive predicates that subsume a diversity of events that range from opinions to accidents and which can be connected to one of the speech-act participants. Egophoric marking also permits inclusion of the third point on the list, namely the reliable information that one of the speech-act participants commits to. In some languages, egophoric markers may be used to mark an event as factual, even when void of the speaker's direct involvement, thereby occurring with events involving third parties of which the speaker can only entertain beliefs (see Floyd et al. 2018). Kamio's theory counts as a pragmatic theory with clear grammatical implications. Reflections of the speaker's territory of information and his/her epistemic authority over this territory can be found in distinct areas of grammar, such as Japanese clause-final particles, evidentials (Grzech 2016), and person markers (Schultze-Berndt 2017), to name just a few. To these we may add modal particles and their functional equivalents (Bergqvist and Knuchel 2017; see directly below).

The above-mentioned generalizations concerning the salience of egophoric aspects of discourse and grammar, both with respect to the referential properties of arguments and the epistemic entailments of self-reference, are important to the rationale of the present investigation, which aims to find support for an analysis of the Swedish modal particles $j u$ and $v a ̈ l$ from their frequency and distribution in spoken Swedish. The idea is that if $j u$ and $v a ̈ l$ encode the epistemic authority of the speech-act participants alongside the speaker's assumption of shared knowledge (engagement), then this should correlate with how these particles are distributed against resources for egophoric reference, namely first, second, and generic pronouns.

\section{Modal particles}

Modal particles are found in all Germanic languages, albeit with differences in the number of forms and their distribution. These differences result from the hypothesized spread of modal particles during the Middle Ages from Low-German varieties to other continental Germanic languages and the Scandinavian languages, including Faroese and Icelandic (both via Danish). While a language like German has at least 16 modal particles (Braber and McLelland 2010: 462), Icelandic has four, according to Hilmisdóttir (2011). ${ }^{6}$ Continental Germanic languages like Dutch and German furthermore allow for stacking of modal particles to form

6 Hilmisdóttir (2011) calls modal particles ‘tone particles'. 
combined expressions with distinct meanings and uses, e.g., ja doch (see Braber and McLelland 2010, for a discussion). This is not found in e.g., Swedish and Norwegian, although it is possible for more than one modal particle to occur in the same utterance (see Section 4.1, below).

Most available studies treat modal particles as distinct from other discourse particles, not only because of their syntactic properties, but also based on their semantic characteristics. ${ }^{7}$ The syntactic features of modal particles are comparable but not identical across Germanic languages. In German, modal particles occupy the middle field, following the subject slot and the finite predicate:

$\begin{array}{llll}\text { Haider } & \text { war } & \text { ja } & \text { betrunken } \\ \text { PN } & \text { be.PST } & \text { MP } & \text { drunk }\end{array}$

'Haider was obviously drunk.'/'Of course, Haider was drunk.' (Abraham and Leiss 2012: 7 [my adjusted glossing and translation])

Other noted formal characteristics concern their combinability (see directly above) and the absence of phonemic stress. Semantically, modal particles target aspects of intersubjectivity (Izutsu and Izutsu 2013) and the relationship between the speaker and hearer (Waltereit 2001). The German modal particle ja ("as you know"/“of course”) has been described as a marker of 'two-fold deixis' that also accommodates the origo of the addressee: "The speaker makes an estimate about the knowledge awareness of the Addressee while letting the Addressee know about this estimate and giving him a chance to relativize, or correct, this estimate" (Abraham and Leiss 2012: 7-8).

Gast (2008) accounts for the German modal particles ja, wohl, doch and etwa in terms of utterance interpretation and relevance theory (Sperber and Wilson 1986). He aims for a systematic classification of the four modal particles, which he regards as constituting "a system of oppositions with pairs of minimally contrasting elements" (Gast 2008: 1). To achieve this, he postulates two parameters: (i) strength of assertion (i.e., fact vs. hypothesis) and (ii) consistency with the relevant context (Gast 2008: 5). The investigated forms are postulated to differ as to whether a marked utterance aligns with some aspect of the referential context, and whether the utterance constitutes a strong or weak assertion and could be viewed as a fact or a hypothesis. According to this analytical model, ja and wohl both align with the relevant context (one aspect of which, is shared knowledge/access), but they contrast in terms of strength of assertion, where ja marks factive utterances and wohl signals a hypothetical assertion. While specifically situated in a theoretical

7 Discourse particles are syntactically unrestricted in comparison to modal particles and their semantics are also less easily defined given their primary discourse-orienting function. 
framework connected to relevance theory, Gast's analysis echoes with accounts of cognate markers in Swedish, to which we now turn.

\subsection{Modal particles in Swedish}

Swedish has four modal particles according to Lindström (2008): ju, väl, nog, and $n u$. The treatment of modal particles in the Swedish reference grammar, SAG (Teleman et al. 1999: 99) uses the notion of "modal clause adverbials" and Eriksson (1988: 75) calls them "unstressed speech-act adverbials". The particles då and visst are grouped with the aforementioned forms in both of these works, but for the purposes of the present investigation, the precise classification of these forms as modal, or discourse particles, is not crucial.

Modal particles are frequent in spoken Swedish; this fact is noted in several works devoted to their description (e.g., Aijmer 1977; Eriksson 1988; Saari 1995). Modal particles are, however, generally not viewed as part of core grammar given their non-obligatoriness, covert paradigmatic organization, and numerous functions with respect to discourse management and the modification of communicative intentions. The syntactic properties of Swedish modal particles approximate those of German modal particles and are also placed in the 'middle field', although the definition of the middle field in Swedish differs slightly from that of German (cf. Jacobs 1991). The syntactic properties of $j u$ and $v \ddot{a} l$ are identical, meaning that any instance of $j u$ in the examples below can be substituted by väl although the utterance meaning will change according to their different semantics (see below).

$J u$ and $v a ̈ l$ cannot be placed sentence-initially, nor as an initial annex (Teleman et al. 1999: 114). This separates them from the other modal particles, nog and $n u$, which can occur sentence-initially. Both ju and $v a ̈ l$ are also restricted to occur in main, declarative clauses (7) and subordinate clauses that are presupposed to be true (8):

$\begin{array}{llllll}\text { Din bror har ju varit } i & \text { Kina } \\ \text { 2POSS } & \text { brother } & \text { have } & \text { MP.ju } & \text { be.PRF in } & \text { China }\end{array}$

(Teleman et al. 1999: 114)

$\begin{array}{lllllll}\text { Om } & \text { din } & \text { bror } & \text { hade } & \text { varit } & i & \text { Kina } \\ \text { If } & \text { 2poss } & \text { brother } & \text { have.PST } & \text { be.PRF } & \text { in } & \text { China } \\ \text { så } & \text { hade } & \text { han } & j u & \text { kunnat berätta } & \\ \text { CONN } & \text { have.PST } & \text { he } & \text { MP.ju } & \text { can.PRF } & \text { tell } & \\ \text { 'If your brother had been to China, he could have to told you.' } \\ \text { (Teleman et al. 1999: 114) }\end{array}$


It is possible to place $j u$ and väl sentence-finally (9), and in certain varieties of Swedish, they can also be doubled (10), but Swedish modal particles cannot be stacked to form combined instances of forms as in German (e.g., Gast 2008: 20-22). Teleman et al. (1999: 115) also note that ju and väl cannot co-occur due to their contrasting semantics.

$\begin{array}{lllllll}\text { Då kan man inte hjälpa honom } & \text { över } & \text { gränsen } & \text { ju } \\ \text { then can one not help } 30 & \text { over border.DEF } & \text { MP.ju }\end{array}$
'(Of course) then you can't help him get across the border.' (Teleman et al. 1999: 114)

(10) Men det verkar ju inte som dom får det ändå ju. but it seem.PRS MP.ju not like 3PL get 3S still MP.ju 'But it certainly doesn't seem like they are getting it anyway'.

(Teleman et al. 1999: 114)

The syntactic properties of $j u$ and $v a ̈ l$ set them apart from nog and $n u$, and their semantics strengthen a view of $j u$ and $v a ̈ l$ as paradigmatically contrastive.

\subsection{The semantics of $j u$ and väl}

Aijmer (1977) treats $j u$ and $v a ̈ l$ as pragmatic indicators in terms of how an utterance containing either marker should be interpreted by the addressee. The meaning of both markers is as such identical to their communicative functions (Aijmer 1977: 206). Alongside this pragmatically oriented analysis of ju and väl, Aijmer also points to modal components in terms of the speaker's attitude and evidence for an utterance found with both markers. Aijmer states that ju marks a proposition as obviously true or constituting a fact, expressing the speaker's conviction that something is true (Aijmer 1977: 207). Väl, on the other hand, signals possibility or that some proposition has a reasonable chance to be true (Aijmer 1977: 211). The modal component of both forms thus differs according to their respective level of certainty, an analysis that aligns with Gast's proposal for ja and wohl in German (see Section 4, above). With respect to the pragmatic functions of $j u$ and $v \ddot{a} l$, both markers are used to relate the proposition that they mark to the addressee in terms of shared knowledge or shared access to the contents of the proposition.

$J u$ can be used to remind the addressee of something (11) but it can also be used in an argumentative sense to convince the hearer by creating "false presuppositions" in an attempt to manipulate the hearer's position with respect to the proposition (12): 


$\mathrm{Du}$ kan ju öppna dörren om det är varmt.
2s can MP.ju open door.DEF if it is warm
'You can, of course, open the door if it's hot.'

(Aijmer 1977: 208)

$\begin{array}{lllllll}N i & \text { var } & \text { ju } & \text { på brottsplatsen } & \text { när } & \text { mordet } & \text { ägde } \\ \text { 2PL } & \text { be.PST } & \text { MP.ju } & \text { at crime_scene.DEF } & \text { when } & \text { murder.DEF } & \text { take.PST } \\ \text { rum, eller } & \text { hur? } & & & & \\ \text { place } & \text { or } & \text { how } & & & & \end{array}$

'You were at the scene of the crime when the murder took place, weren't you?' (Aijmer 1977: 209)

Aijmer also points to ju's rhetorical function in signaling that the addressee should know or pay attention to something. Ju can also be used to signal that the speaker him/ herself should know or attend to something that is accessible to the speaker (13): ${ }^{8}$

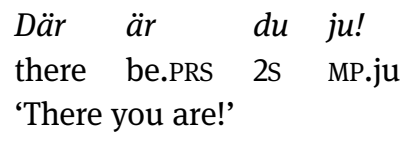

(Aijmer 1977: 210)

The pragmatic functions of väl target the addressee's perspective and the addressee's epistemic authority. ${ }^{9}$ In using väl, the speaker wishes to check whether the proposition contained within the utterance is true or not, by deferring to the addressee's epistemic authority. The addressee is thereby invited to verify or correct the speaker's belief that the uttered proposition is true:

$\begin{array}{lllll}\text { Den där klänningen var väl } & d y r ? \\ \text { DEM there dress } & \text { be.PST } & \text { MP.väl } & \text { expensive } \\ \text { 'That dress was expensive, right?' } & & \end{array}$

(Aijmer 1977: 212)

8 A reviewer noted a 'mirative' connotation in (13). The same reviewer also points out the fact that there are uses of $j u$ and $v a ̈ l$ that are not obviously reducible to the notion of engagement. This observation does not contradict the account of $j u$ and $v a ̈ l$ in the present paper; there are uses of e.g., $j u$ that cannot be reduced to a notion such as 'shared access', but it is argued that shared access is a nondefeasible component of $j u$, even when this semantic component coincides with other aspects of epistemicity, such as mirativity. The particle-status of $j u$ and $v a ̈ l$ means that they are susceptible to contextual cues, but there is reason to argue for non-reducible meaning content in both forms (see e.g., Gast (2008) regarding functionally equivalent German modal particles).

9 The Swedish phrase that Aijmer (1977) uses is kunskapsmässig auktoritet, which translates quite well to the term 'epistemic authority', although this concept was largely unused in the literature on modality and discourse marking at that time. 


Du har väl hört vad som hänt.
2S have MP.väl hear.PST what REL happen.PST
'You heard what happened, right?'

(Aijmer 1977: 212)

$V a ̈ l ~ c a n$ also be used in commands and requests but with an added appeal to the addressee's ability and willingness to accommodate the speaker's request for the addressee's action:

Du kan väl låna mig en tia?
$2 \mathrm{~s}$ can MP.väl lend 1s.o one ten_note
'Lend me a tenner, will you?'

(Aijmer 1977: 213)

Aijmer also notes that there is a politeness dimension to the use of $v a ̈ l$, where the insertion of $v a ̈ l$ in a potentially face-threatening statement mitigates the effect of such a statement. In fact, one of the most salient aspects of väl, according to Aijmer, is to express deference to the addressee, a function that supersedes the speaker's attitude to the proposition.

In conclusion, Aijmer argues that the modal meaning component of $j u$ and $v a ̈ l$ is insufficient to analyze the two markers and that consideration must be given to the interaction between the speaker and the addressee. While ju signals the addressee's (shared) access to knowledge, $v a ̈ l$ expresses an appeal to the hearer to concur and confirm the speaker's proposal as contained in his/her utterance. This estimation aligns with the proposal of the present paper, viz. to find evidence for the definition of $j u$ and $v a ̈ l$ from how they map onto subject person. If deference to the hearer is a central meaning component of $v \ddot{a} l$, then it is reasonable to expect to find $v a ̈ l$ more often with the second-person subject pronoun, $d u$, than with other subject persons. A similar expectation also goes for $j u$ with regard to first-person subjects. Such distributional patterns is the topic of Section 5, below.

\section{The frequency and distribution of $j u$ and väl in spoken Swedish}

The frequency of modal particles in spoken Swedish has been noted in the literature going back to at least the 1980s. Eriksson (1988) investigated ju, väl, $d a ̊, v a$, altså in spoken Swedish with the aim to analyze these particles from how they occur in spoken interaction. While Eriksson considers ju, väl, då, $v a$, 
alltså to be part of a group of forms that also includes less formalized constructions (i.e., ones that would not be called modal particles in the strict sense, e.g., det är klart "of course"), he characterizes such forms as non-propositional as they primarily convey aspects of the speaker's attitude towards some proposition and because they lack referential content (Eriksson 1988: 75). Out of all investigated forms and constructions in Eriksson's corpus, ju and väl make up 226 of 398 (57\%; Eriksson 1988: 90) with $j u$ amounting to $72 \%$ of these (164 instances). ${ }^{10} \mathrm{Då}$ and nog only account for 15 and 12 instances, respectively, which suggests the special status of $j u$ and $v a ̈ l$ in terms of frequency. Eriksson notes the high number of instances of $j u$ and also states that $j u$ is difficult to define given the numerous, many-faceted functions that it serves; the three most common functions being, i) to clarify the connection between utterances, ii) to express a proposition as obvious, based on shared experience, iii) to express personal conviction in an argumentative sense (Eriksson 1988: 92).

$V a ̈ l$ is the second most common form and signals the speaker's estimation that a proposition is likely to be true and a request for agreement from the addressee. However, Eriksson also notes instances of $v a ̈ l$ where the speaker's estimation that a proposition is likely to be true disappears completely, leaving only a request for the addressee's agreement. Eriksson characterizes some such instances of väl as expressing "low engagement", or something as "being obvious” (Eriksson 1988: 98). These instances also connect $v a ̈ l$ to ju, and there are examples where one could be substituted for the other without a noticeable difference.

Eriksson concludes by stating that the speaker's knowledge about the contents of an utterance plays a subordinate role in the definition of $j u$ and $v \ddot{a} l$. The most important factor that accounts for the use of the investigated forms (in the part of the corpus that consists of an open discussion) is to relate utterances to the addressee and not to state the speaker's commitment to the truth of the utterance (Eriksson 1988: 118). These observations are in agreement with the present analyses of $j u$ and $v a ̈ l$, which places emphasis on shared access as a non-defeasible meaning component of both forms.

\section{1 "Conversations in Gothenburg": A corpus of spoken Swedish}

The present investigation uses a half-million word corpus of spoken Swedish called Conversations in Gothenburg (Sv. Samtal i Göteborg; CG, henceforth) as

10 The total number of forms in Eriksson's corpus is 398 and ju and väl amount to 226 of these. 
material for its analysis. This is the same corpus that Dahl (2000) used to extract a sub-corpus of some 65.000 words that he called "the G corpus" (Dahl 2000: 41). This corpus was collected as part of a sociolinguistic project where participants were asked to record themselves having a conversation with another person (Löfström 1988, in Dahl 2000: 41). This method of data collection affords a level of naturalness to the conversation that is unusual for larger spoken language corpora. For the purpose of his investigation, Dahl tagged his subcorpus of 65.000 words in order to be able to classify all arguments and predicates therein. The full half-million word corpus used in the present investigation is not tagged and therefore does not permit a comparable precision search for relevant forms, but for the purpose of the present investigation this is not necessary (see below, for details). ${ }^{11}$

More precisely, the corpus consists of 497.677 words, segmented into around 50.700 lines, which approximates turns and yields roughly 10 words per turn. There are 7323 instances of $j u$ and 2223 of $v a ̈ l$ in the corpus giving a total of 9546 instances for both forms. ${ }^{12}$ The proportion of $j u$ is $77 \%$ against $23 \%$ for $v a ̈ l$, meaning that $j u$ is over three times more common than $v a ̈ l$. The total number of both particles corresponds to $1.9 \%$ of all words in the corpus, and occurs in around 19\% of all lines/turns. Of the other modal particles, nog has 739 occurrences and $n u$, which does double duty as a time adverbial, has 2210 occurrences even though many of these may be attributed to this primary function. ${ }^{13}$

To contextualize these numbers, the number of egophoric subject pronouns (jag/du/man) are 25.821. Of these, jag accounts for 13.768 instances, $d u$ for 7248 , and man for 4805. From these numbers we can gather that the second most common egophoric subject pronoun, $d u$, is comparable in number to the most common modal particle, $j u$. If we consider the fact that Swedish grammar has syntactically obligatory subject marking, this is worth noting. Modal particles are

11 The choice to use the CG-corpus was conditioned by accessibility and previous familiarity but also by the spontaneous, natural character of the spoken language data.

12 There is a homographic form, väl ("well"), with a long vowel. The number of instances of this form appears marginal given that a search of common collocations such as mycket väl ("very well”), lite väl ("a bit too"), and lika väl ("just as well”), only produced 24 instances, combined. These forms have a different distribution and are not included in the present count. The same is true for $j u$, which has a homonym with the function of indicating 'gradual increase/decrease' of some quantity, like in ju mer desto bättre ('the more, the better'). Some 15 instances of this form have been identified, which means this form is also rather peripheral.

13 A discourse-managing function must be regarded as secondary to other functions that target less abstract domains, such as time and the sequentiality of events. One reviewer noted that $n u$ counts as a modal particle in Finnish varieties of Swedish, but not in mainland varieties. 
comparable to pronouns in number although their non-obligatoriness makes them less frequent in terms of total numbers in the corpus. ${ }^{14}$

\section{2 ju and väl in the CG-corpus}

Since the aim of the investigation is to find support for an analysis of $j u$ and $v a ̈ l$ as engagement markers based on their distribution with egophoric referents ( $j a g, d u$, man), a subset of the total number of forms was extracted, for stated reasons. In total, 2920 instances of $j u$ and $v a ̈ l$ were collected. The distribution of $j u$ and $v a ̈ l$ in this subset corresponds exactly to the one found with the total number of forms, namely $76 \%$ (2215) for $j u$ and 24\% (705) for väl. These results are presented in Table 1, where the subsets for $j u$ and väl may be compared:

To contextualize these percentages, Table 2 provides a frequency count and percentage distribution of subject pronouns in the total corpus.

Some percentages stand out in a comparison between the tables above. Notable differences mainly revolve around the egophoric referents, first-person

Table 1: Co-occurrences of subject pronouns with ju/väl.

\begin{tabular}{|c|c|c|c|c|}
\hline & \multicolumn{2}{|c|}{ Raw frequencies } & \multicolumn{2}{|c|}{ Relative frequencies } \\
\hline & $J u$ & Väl & $J u$ & $V \ddot{a}$ \\
\hline Jag & 312 & 62 & $14 \%$ & $9 \%$ \\
\hline$D u$ & 113 & 86 & $5 \%$ & $12 \%$ \\
\hline Han & 138 & 34 & $6 \%$ & $5 \%$ \\
\hline Hon & 47 & 37 & $2 \%$ & $5 \%$ \\
\hline Den & 64 & 20 & $3 \%$ & $3 \%$ \\
\hline Det & 666 & 223 & $30 \%$ & $32 \%$ \\
\hline Man & 404 & 70 & $18 \%$ & $10 \%$ \\
\hline$V i$ & 208 & 88 & $9 \%$ & $12 \%$ \\
\hline $\mathrm{Ni}$ & 15 & 7 & $>1 \%$ & $1 \%$ \\
\hline Dom & 248 & 78 & $11 \%$ & $11 \%$ \\
\hline Total & 2215 & 705 & $100 \%$ & $100 \%$ \\
\hline
\end{tabular}

14 A reviewer commented on the strikingly high numbers for $j u$ and suggested that this may be a product of genre and the idiosyncratic use of forms by speakers. Inter-speaker variation in the use of epistemic markers has been noted in the literature, and genre most likely plays a role with regard to frequency. Unprompted face-to-face conversation must be regarded as a basic communicative setting, however, and the (potential) preference by some speakers to use modal particles is not something that can be controlled for in the present investigation given the restricted materials that it is based on. 
Table 2: Numbers and percentages of subject pronouns in the corpus.

\begin{tabular}{lrr}
\hline Subject pronoun & Raw freq. & Rel. freq. \\
\hline Jag & 13,768 & $17 \%$ \\
Du & 7248 & $9 \%$ \\
Han & 4194 & $5 \%$ \\
Hon & 2744 & $3 \%$ \\
Den & 4693 & $6 \%$ \\
Det & 29,135 & $36 \%$ \\
Man & 4805 & $6 \%$ \\
Vi & 5511 & $7 \%$ \\
Ni & 543 & $>1 \%$ \\
Dom & 7420 & $9 \%$ \\
\hline Total & 80,061 & $100 \%$ \\
\hline
\end{tabular}

jag, second-person $d u$, and especially the generic pronoun man. These forms are differently distributed against $j u$ and $v a ̈ l$ when comparing the frequencies displayed in Table 1 to the absolute frequencies of pronouns in Table 2. Combinations of non-egophoric subject pronouns (hon/han/den/det/dom) and ju/väl are mostly proportionate. $^{15}$

Jag is slightly less frequent with $j u$ compared to its absolute number while $d u$ displays a reduction by almost half. Vi and man are more frequent. Man stands out in this comparison: it is three times more frequent with $j u$ compared to its absolute numbers. While the percentage of man $+j u$ is three times that of man in absolute numbers, $j a g+j u$ amounts to a little over $80 \%$ of jag in absolute numbers. Combinations of $d u / m a n$ and $v a ̈ l$ show higher frequencies compared to their absolute numbers, while jag and väl aremuch less frequent compared to the absolute numbers for jag. The percentages for combinations of the egophoric pronouns jag/ $d u /$ man and the modal particles $j u / v a ̈ l$ are summarized in Table 3:

Table 3: Comparison of co-occurrences of jag/du/man with ju/väl.

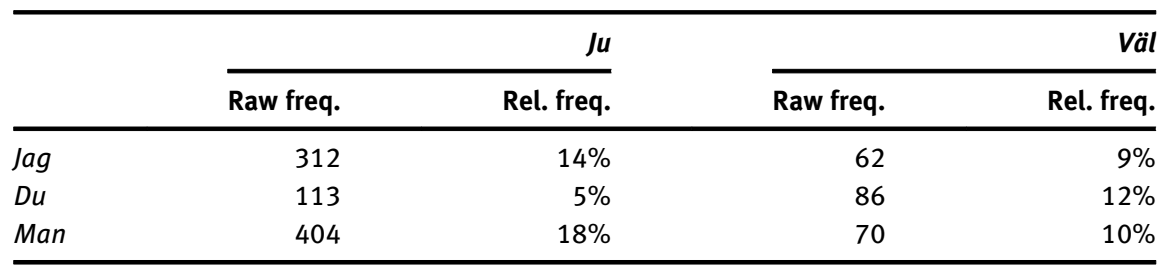

15 There is a difference in the percentages for the third person feminine subject pronoun, hon with $j u(2 \%)$ and $v a ̈ l(5 \%)$ that approximates what can be observed for $d u$. The number of co-occurrences of hon with $j u / v a ̈ l$ is proportional against the absolute frequency of this pronoun, however. 
Table 3 offers a relativized view of how egophoric pronouns combine with the modal particles $j u$ and väl. In a comparison between pronouns, jag primarily occurs with $j u$ and $d u$ primarily with $v a ̈ l$. The combination of $d u$ and $j u$ only amounts to $5 \%$ of all subject pronouns whereas the numbers for $d u$ and $v a ̈ l$ are $12 \%$, the highest percentage for all combinations of egophoric pronouns and väl. Jag goes in the opposite direction with $14 \%$ of co-occurrences with ju and $9 \%$ with $v a ̈ l$.

The generic pronoun man accounts for the highest number of occurrences with $j u(18 \%)$ and almost identical percentages to jag in combination with väl (man + väl: 10\% vs. jag + väl: 9\%). Based on a relative comparison of percentages, man behaves like first-person jag, given that it is almost twice as common with ju as with väl. The percentages for man in combination with $j u / v a ̈ l$ point to a primary reference to the speaker (first person) even though the referential meaning of man potentially also includes other, unspecified referents (not excluding the addressee). We may, in fact, characterize the observed differences between jag/ man and $d u$ as a 'flip' of percentages between co-occurrences of $j u$ and $v a ̈ l$ with these pronouns; the percentage of co-occurrences between $d u+j u(5 \%)$ is more than doubled with $d u+v \ddot{a} l(12 \%)$ whereas the percentage of co-occurrences between $j a g+j u(14 \%)$ is reduced by a third with jag + väl (9\%). Man aligns with jag, with a reduced percentage between $j u(18 \%)$ and $v a ̈ l ~(10 \%)$.

There is no corresponding flip observed for percentages with $j u / v a ̈ l$ and firstperson plural vi/second-person plural $n i$. But, there are also very few instances of $n i$ and $j u / v a ̈ l$, so it is difficult to compare this pronoun with the singular $d u$. For the first-person plural pronoun, vi, however, the change in percentages align with the second-person $d u$ more than it does with first-person jag. The relative difference in percentage between $v i+j u(9 \%)$ and $v i+v \ddot{a} l(12 \%)$ is less than for $d u+j u / v a ̈ l(5 \%)$ $14 \%$ ), but it agrees with the general direction of change. These percentages suggest that the referential salience of second person is high in the use of $v i$ and that from a cross-linguistic perspective, where first-person markers can be 'inclusive' (me and you), or 'exclusive' (me and others, excluding you), the primary use of the Swedish $v i$ resembles the inclusive kind in the investigated materials.

$J u$ and $v a ̈ l$ are distributed against first-person (jag), generic-person (man), and second-person $(d u)$ subjects according to their proposed function as signaling the speaker's and the addressee's epistemic authority. An absolute comparison of percentages between $j u+j a g / m a n$, and $v a ̈ l+d u$ in Table 4 reflects this function:

Table 4 shows the co-distribution between egophoric pronouns and ju/väl in terms of percentages for respective combinations. The generic man stands out with the highest percentage (49\%) in combination with $j u$ and a high percentage (32\%) with $v a ̈ l . ~ D u+j u$ only accounts for $13.5 \%$, but $d u+v \ddot{a} l$ amounts to $39 \%$. Jag $+j u$ makes up $37.5 \%$, but jag + väl has the lowest percentage of all egophoric pronoun $+v a ̈ l$-combinations, with $28 \%$. From these numbers, it is reasonable to 
Table 4: Relativized comparison between jag/man/du with ju/väl.

\begin{tabular}{lrrrr}
\hline & Jag (1s) & Man (GEN) & Du (2s) & Total MPs \\
\hline Ju & $312(37.5 \%)$ & $404(49 \%)$ & $113(13.5 \%)$ & 829 \\
Väl & $62(28 \%)$ & $70(32 \%)$ & $86(39 \%)$ & 218 \\
Total EGO PRNs & 374 & 474 & 199 & 1047 \\
\hline
\end{tabular}

view the generic man as an egophoric pronoun that occupies a middle-ground between first-person jag and second-person $d u$; man frequently combines with both ju and väl. The generic meaning of man accommodates the notion of 'sharedness' that has been argued to be a non-defeasible feature of $j u$ and $v a ̈ l$, thus making it a prime candidate for co-distribution with these particles. This is also what the percentages suggest. The percentages of man in combination with ju/väl, further suggest that reference to the speaker, as part of the generic meaning of man, produces a distributional pattern that resembles that of jag with higher percentages for man + ju than man + väl.

Finally, some comments should be made concerning the frequency of $j u / v a ̈ l ~ i n$ combination with non-egophoric pronouns. The most common pronoun to combine with $j u / v a ̈ l$ in the material is the third-person impersonal pronoun den/ det. These combine in 33\% cases with $j u$ and in $35 \%$ with väl counting all occurrences in the material. However, there is a marginal difference between these combinations, which makes them less relevant for the purpose of the study. The high percentages can be accounted for by predicative constructions, which, as noted by Dahl (2000), is a construction type that favors third-person referents. For example, the predicative vara ("be"/'exist'W) accounts for more than $21 \%$ of all combinations with den/det and ju/väl, alone (1618). The percentages in Table 1 suggest that the distribution of $j u / v a ̈ l$ with non-egophoric referents i.e., han, hon, den, det, dom combine with ju in 52\% of all cases and with väl in $56 \%$ of all cases. This even co-distribution of forms means that there is nothing special about how

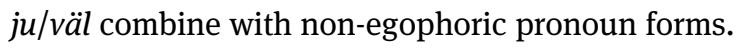

\section{Discussion of results: ju and väl as markers of engagement}

The underlying rationale of the present investigation rests on two well known observations, namely that (i) there is a connection between frequency and degree of grammaticalization, where functional lexemes are more frequent than ones with lexical semantic content, and (ii) that the distribution of a functional lexeme is an 
indicator of its functional status against other grammatical forms. Both observations have relevance for the present investigation, which argues that evidence for the meaning of modal particles $j u$ and $v a ̈ l$ can be found in the way these markers are distributed against egophoric subject pronouns in spoken Swedish. Their frequency also indicates the grammatical status of both modal particles as epistemic markers. The descriptive tradition of language specific constructions and forms sometimes stands in the way of permitting a clear comparison to related, but descriptively distinct forms. This is a well known obstacle in typological research, but it is also an issue for individual language descriptions, where forms like modal particles may be overlooked in grammatical accounts and regarded as peripheral to such descriptions. The results of the investigation may be stated in the following way: the frequency of $j u / v a ̈ l$ in spoken Swedish indicates their important role in signaling the speech-act participants' epistemic attitudes regarding events. The frequent presence of $j u / v a ̈ l$ in discourse justifies regarding them as grammatical, albeit not obligatory, and the distribution of both markers against egophoric pronouns supports an analysis of their semantics in terms of epistemic authority. The claims forwarded here may have general applicability for analyses of modal particles in other languages, but this possibility requires further study in order to be empirically confirmed.

In a previous study of egophoric reference in discourse by Dahl (2000), egophoric referents are observed to constitute the majority of all animate arguments in spoken Swedish, Spanish, and English. People who are engaged in conversation with no other goal than to talk with each other, prefer to talk about themselves (speaker/addressee) rather than about people who are not present in the conversation. In written genres, the reverse is true; egophoric reference is dispreferred and replaced by non-egophoric referents. The present investigation is based on the same material used by Dahl but focuses on the epistemic side of egophoricity (cf. Floyd et al. 2018). Ever since Goffman's (1981) proposal to view the speaker as occupying three separate roles, namely the one who decides what to say (author), the one who produces the utterance (animator), and the one who is accountable for the utterance (principal), it has been clear that the qualification of knowledge has an inherent connection to a speaker who is also the principal speaker, and that this is implicitly present in the use of pronouns and person markers in language.

$J u$ and $v a ̈ l$ are paradigmatically contrastive in expressing shared access to an event from the perspective of one of the speech-act participants. The shared grammatical status of $j u$ and $v a ̈ l$ also contrasts with other modal particles, thus providing support for a paradigmatic view of these forms (see Section 4.2, above). The main proposal of the present paper is that ju signals shared access to an event and at the same time places the epistemic authority with the speaker, while väl signals shared access to an event along-side the epistemic authority of the 
addressee. From the point of view of epistemic marking, there are aspects of egophoric marking and engagement encoded in both forms. The prolific codistribution of $j u$ with the generic pronoun man is indicative of the proposed engagement semantics for ju. Man is a pronoun that non-exclusively targets the speaker, with implicit reference to other participants. Its frequent occurrence with $j u$ aligns with a semantic analysis in terms of sharedness.

As stated in Section 2, engagement signals the assumed sharedness/nonsharedness between the speech-act participants with respect to any aspect of epistemicity, such as belief, perceptual/cognitive access, and involvement (Bergqvist and Knuchel 2019; Bergqvist and Kittilä 2020). While ju and (to a lesser extent), väl, have been defined by their function to qualify the truth content of a proposition (e.g., Aijmer 1977, 1996; Eriksson 1988; Teleman et al. 1999; cf. Gast 2008 for German), it is their intersubjective semantics that separates them from other discourse markers (e.g., Izutsu and Izutsu 2013). $J u$ and $v a ̈ l$ share semantic features with the engagement markers ni-/shi- in Kogi (Section 2.1), i.e., shared-knowledge access while contrasting in terms of who is epistemic authority: the speaker, or the addressee. It is evident that 'speaker authority' (ju) is conceptualized as strong assertion, while addressee authority, (väl), by contrast, is conceived of as signaling reduced certainty, or a hypothesis on the part of the speaker (see Gast 2008). As noted by Eriksson (1988), however, such (epistemic) modal meanings may disappear in the contextualized use of forms while the communicatively motivated function of $j u$ and väl, viz. to signal authority, persist. Aijmer (1977), Eriksson (1988), and Teleman et al. (1999) all point to the agreement-seeking function of $j u$ and $v a ̈ l$, and it is this functional commonality that underlies their analysis in terms of engagement (i.e., signaling shared access to an event). This shared feature also makes visible their distinct functions with respect to the placement of epistemic authority with the speaker or the addressee.

The proposed definitions of modal particles in German as illocutionary modifiers (Jacobs 1991) and markers of 'double deixis' (Abraham and Leiss 2012) may be nuanced by a closer look at the distribution of such forms against subject pronouns. The function of Swedish ju and $v \ddot{a} l$ as markers of the speaker's and the addressee's epistemic authority, is a function that might be overlooked if such distributions are not taken into account. The co-occurrence of modal particles with other relevant parts of grammar may in this way serve as an indicator of their semantics and grammatical status.

Acknowledgments: The author wishes to acknowledge the intellectual and practical efforts of Karolina Grzech and Eva Schultze-Berndt who co-organized the workshop in which this paper was first presented and later initiated the editorial process for the present Special Issue. Thanks also to two reviewers for their insightful and constructive comments and to the Editors of Folia Linguistica for their efforts and kind guidance. Financial support for the research on which the 
paper builds was provided by the Swedish Research Council (dnr. 2017-01969) and Marcus and Amalia Wallenbergs Minnesfond (MAW 2017.0081).

\section{Abbreviations}

$\begin{array}{ll}1 & \text { first person } \\ 2 & \text { second person } \\ 3 & \text { third person } \\ \text { S } & \text { singular } \\ \text { ADR } & \text { addressee } \\ \text { ASYM } & \text { asymmetric } \\ \text { COMP } & \text { completive } \\ \text { CONN } & \text { connective } \\ \text { DEF } & \text { definite } \\ \text { DEM } & \text { demonstrative } \\ \text { EGO } & \text { egophoric } \\ \text { IMPF } & \text { imperfective } \\ \text { IND } & \text { independent } \\ \text { INTERR } & \text { interrogative } \\ \text { LOC } & \text { locative } \\ \text { MP } & \text { modal particle } \\ \text { NON.EGO } & \text { non-egophoric } \\ \text { O } & \text { object } \\ \text { PL } & \text { plural } \\ \text { PN } & \text { proper name } \\ \text { POSS } & \text { possessive } \\ \text { PRF } & \text { perfect } \\ \text { PRS } & \text { present } \\ \text { PST } & \text { past } \\ \text { REL } & \text { relative pronoun } \\ \text { SPKR } & \text { speaker } \\ \text { SYM } & \text { symmetric } \\ & \\ & \end{array}$

\section{References}

Abraham, Werner \& Elisabeth Leiss (eds.). 2012. Modality and theory of mind elements across languages (Trends in Linguistics Studies and Monographs 243). Berlin: Walter de Gruyter. Aijmer, Karin. 1977. Partiklarna ju och väl [The particles ju and väl]. Nysvenska studier 57. 205-216.

Aijmer, Karin. 1996. Swedish modal particles in a contrastive perspective. Language Sciences 18(1-2). 393-427.

Benveniste, Émile. 1971 [1966]. Problems in general linguistics. Coral Gables: University of Miami Press. 
Bergqvist, Henrik. 2015. Epistemic marking and multiple perspective: An introduction. STUF Language Typology and Universals 68(2). 123-141.

Bergqvist, Henrik. 2016. Complex epistemic perspective in Kogi (Arwako). International Journal of American Linguistics 82(1). 1-34.

Bergqvist, Henrik. 2017. The role of 'perspective' in epistemic marking. Lingua 186-187. 5-20.

Bergqvist, Henrik. 2018a. Evidentiality as stance: Event types and speaker roles. In Ad Foolen, Helen de Hoop \& Gijs Mulder (eds.), Evidence for evidentiality (Human Cognitive Processing 61), 19-43. Amsterdam: John Benjamins.

Bergqvist, Henrik. 2018b. Intersubjectification revisited: A cross-categorical perspective. In Zlatka Guentcheva (ed.), Epistemic modalities and evidentiality in cross-linguistic perspective (Empirical Approaches to Language Typology 59), 319-345. Berlin: Mouton de Gruyter.

Bergqvist, Henrik \& Seppo Kittilä. 2020. Epistemic perspectives: Evidentiality, egophoricity, and engagement. In Henrik Bergqvist \& SeppoKittilä (eds.), Evidentiality, egophoricity, and engagement (Studies in Diversity Linguistics 99). Berlin: Language Science Press.

Bergqvist, Henrik \& Dominique Knuchel. 2017. Complexity in egophoric marking: From agents to attitude holders. Open Linguistics 3. 359-377.

Bergqvist, Henrik \& Dominique Knuchel. 2019. Explorations of engagement: Introduction. Open Linguistics 5. 650-665.

Braber, Natalie \& Nicola McLelland. 2010. Combining modal particles in German and Dutch. Journal of Germanic Linguistics 22(4). 461-482.

Burenhult, Niclas. 2003. Attention, accessibility, and the addressee: The case of the Jahai demonstrative ton. Pragmatics 13. 363-379.

Bybee, Joan L, Revere Perkins \& William Pagliuca. 1994. The evolution of grammar: Tense, aspect and modality in the languages of the world. Chicago: The University of Chicago Press.

Creissels, Denis. 2008. Person variation in Akhvakh verb morphology: Functional motivation and origin of an uncommon pattern. STUF - Language Typology and Universals 61(4). 309-325.

Curnow, Timothy J. 2002. Conjunct/disjunct marking in Awa Pit. Linguistics 40(3). 611-627.

Dahl, Östen. 2000. Egophoricity in discourse and grammar. Functions of Language 7(1). 37-77.

Dimmendaal, Gerrit J. 2001. Logophoric marking and represented speech in African languages as evidential hedging strategies. Australian Journal of Linguistics 21(1). 131-157.

Eriksson, Mats. 1988. Ju, väl, då, va, alltså. En undersökning av talaktsadverbial i stockholmskt talspråk [Ju, väl, då, va, alltså. An investigation of speech-act adverbials in spoken Stockholmese]. In Amelie Schenström \& Mats Eriksson (eds.), Studier i stockholmsspråk 1 (MINS 26), 75-120. Stockholm: Institutionen för nordiska språk.

Evans, Nicholas R. 2005. View with a view: Towards a typology of multiple perspective. Berkeley Linguistics Society (BLS) 31. 93-120.

Evans, Nicholas, Henrik Bergqvist \& Lila San Roque. 2018a. The grammar of engagement I: Framework and initial exemplification. Language and Cognition 10(1). 110-140.

Evans, Nicholas, Henrik Bergqvist \& Lila San Roque 2018b. The grammar of engagement II: Typology and diachrony. Language and Cognition 10(1). 141-170.

Floyd, Simeon, Elisabeth Norcliffe \& Lila San Roque (eds.). 2018. Egophoricity. Amsterdam: John Benjamins.

Gast, Volker. 2008. Modal particles and context updating: The functions of German ja, doch, wohl and etwa. In Ole Letnes, Eva Maagerø \& Heinz Vater (eds.), Modalität und Grammatikalisierung, 153-177. Trier: Wissenschaftlicher Verlag.

Goffman, Erving. 1981. Forms of talk. Philadelphia: University of Pennsylvania Press. 
Grzech, Karolina. 2016. Discourse enclitics in Tena Kichwa: A corpus-based account of information structure and epistemic meaning. London: SOAS, University of London dissertation. https://eprints.soas.ac.uk/24336/.

Hale, Austin. 1980. Person markers: Finite conjunct and disjunct forms in Newari. In Roland L. Trail (ed.), Papers in Southeast Asian Linguistics, vol. 7, 95-106. Canberra: Pacific Linguistics.

Hilmisdóttir, Helga. 2011. Giving a tone of determination: The interactional functions of nú as a tone particle in Icelandic conversation. Journal of Pragmatics 43. 261-287.

Holmes, Janet. 1984. Modifying illocutionary force. Journal of Pragmatics 8. 345-365.

Izutsu, Katsunobu \& Mitsuko Narita Izutsu. 2013. From discourse markers to modal/final particles: What the position reveals about the continuum. In Liesbeth Degand, Bert Cornillie \& Paola Pietrandrea (eds.), Discourse markers and modal particles: Categorization and description, 217-235: John Benjamins.

Jacobs, Joachim. 1991. On the semantics of modal particles. In Werner Abraham (ed.), Discourse particles: Descriptive and theoretical investigations on the logical, syntactic and pragmatic properties of discourse particles in German, 141-162. London: Routledge.

Jakobson, Roman. 1990 [1957]. Shifters and verbal categories. In Linda R. Waugh \& Monique Monville-Burston (eds.), On language, 386-392. Cambridge: Harvard University Press.

Kamio, Akio. 1997. Territories of information. Amsterdam: John Benjamins.

Klein, Wolfgang. 1994. Time in language. London: Routledge.

Knuchel, Dominique. 2019. Kogi demonstratives and engagement. Open Linguistics 5. 615-629. Kockelman, Paul. 2004. Stance and subjectivity. Journal of Linguistic Anthropology 14. 127-150. Landaburu, Jon. 2007. La modalisation du savoir en langue Andoke (Amazonie Colombienne). In Zlatka Guentchéva \& Jon Landaburu (eds.), L'énonciation médiatisée II - Le traitment épistémologique de l'information: illustrations amérindiennes et caucasiennes, 23-47. Paris: Édition Peeters.

Lindström, Jan. 2008. Tur och ordning: Introduktion till svensk samtalsgrammatik [Turn and order: Introduction to Swedish conversational grammar]. Stockholm: Norstedts.

Lum, Jonathon. 2020. An egophoric analysis of Dhivehi verbal morphology. In Henrik Bergqvist \& Seppo Kittilä (eds.), Evidentiality, egophoricity, and engagement (Studies in Diversity Linguistics 99), 95-139. Berlin: Language Science Press. https://doi.org/10.5281/zenodo. 3975801.

Löfström, Jonas. 1988. Repliker utan gränser: Till studiet av syntaktisk struktur i samtal [Boundless conversational exchanges: A contribution to the study of syntactic structure in conversation]. Gothenburg: University of Gothenburg dissertation.

Ortíz Ricaurte, Carolina. 1994. Clases y tipos de predicados en la lengua Kogui. In Jon Landaburu (ed.), Estructuras sintacticas de la predicación: Lenguas amerindias de Colombia, 377-399. Bogotá: CCELA.

Östman, Jan-Ola. 1981. You know: A discourse functional approach. Amsterdam: John Benjamins.

Plungian, Vladimir. 2010. Types of verbal evidentiality marking: An overview. In Gabriele Diewald \& Elena Smirnova (eds.), The linguistic realization of evidentiality in European languages, 15-58. Berlin: Mouton de Gruyter.

Saari, Mirjaa. 1995. 'Jo, nu kunde vi festa nog'. Synpunkter på svenskt språkbruk i Sverige och Finland ["Well, we could really party". Views on Swedish language use in Sweden and Finland]. Folkmålsstudier 36. 75-108.

San Roque, Lila, Simeon Floyd \& Elisabeth Norcliffe. 2018. Egophoricity: An introduction. In Simeon Floyd, Elisabeth Norcliffe \& Lila San Roque (eds.), Egophoricity, 1-77. Amsterdam: John Benjamins. 
Schultze-Berndt, Eva. 2017. Shared vs. primary epistemic authority in Jaminjung/Ngaliwurru. Open Linguistics 3. 178-218.

Scott-Phillips, Thom. 2015. Speaking our minds: Why human communication is different and how language evolved to make it special. London: Palgrave Macmillan.

Simon-Vandenbergen, Anne-Marie \& Karin Aijmer. 2007. The semantic field of modal certainty: A corpus-based study of English adverbs (Topics in English Linguistics 56). Berlin: Mouton de Gruyter.

Sperber, Dan \& Deidre Wilson. 1986. Relevance: Communication and cognition. Malden, MA: Wiley-Blackwell.

Teleman, Ulf, Staffan Hellberg \& Erik Andersson. 1999. Svenska Akademiens grammatik [Grammar of the Swedish Academy], vol. 4. Stockholm: Norstedts.

Traugott, Elisabeth Closs \& Richard B. Dasher. 2002. Regularity in semantic change. Cambridge: Cambridge University Press.

Tree, Jean E. Fox \& Josef C. Schrock. 2002. Basic meanings of you know and I mean. Journal of Pragmatics 34. 727-747.

Trevarthen, Colwyn. 1979. Communication and cooperation in early infancy: A description of primary intersubjectivity. In Margaret Bullowa (ed.), Before speech: The beginning of interpersonal communication, 321-348. Cambridge: Cambridge University Press.

Verhagen, Arie. 2005. Constructions of intersubjectivity. Discourse, syntax and cognition. Oxford: Oxford University Press.

Waltereit, Richard. 2001. Modal particles and their functional equivalents: A speech-act-theoretic approach. Journal of Pragmatics 33(9). 1391-1418. 